\title{
Pattern of Neonatal Surgical Admissions in University of Uyo Teaching Hospital (UUTH), Uyo
}

\section{Eno Etim Nyong ${ }^{1 *}$, Usen Effiong Uwah ${ }^{2}$, Jacob Jackson Udoh ${ }^{3}$, Paulinus Umoren Essien ${ }^{4}$ and Kingsley Irelosen Akhimeinho ${ }^{4}$}

${ }^{1}$ Department of Paediatrics, University of Uyo Teaching Hospital, Uyo, Akwa Ibom State, Nigeria

${ }^{2}$ MD Specialist Surgeon, Specialist Paediatric Surgeon, Department of Surgery,

University of Uyo Teaching Hospital, Uyo, Akwa Ibom State, Nigeria

${ }^{3}$ Professor, Department of Paediatrics, University of Calabar Teaching Hospital,

Calabar, Cross River State, Nigeria

${ }^{4}$ Department of Paediatrics, University of Uyo Teaching Hospital, Uyo, Akwa Ibom

State, Nigeria

*Corresponding Author: Eno Etim Nyong, Department of Paediatrics, University of Uyo Teaching Hospital, Uyo, Akwa Ibom State, Nigeria.
Received: March 01, 2021

Published: April 19, 2021

(c) All rights are reserved by Eno Etim Nyong., et al.

\section{Abstract}

Background: Surgery in the newborn period is a significant contribution to the specialty of Paediatric Surgery and this involves the surgical management of some of the congenital conditions which form the bulk of these neonatal surgical conditions. The pattern of these surgical presentations has not been documented in Akwa Ibom State.

Objective: To describe the pattern of neonatal surgical admissions seen in the early years of existence of the University of Uyo Teaching Hospital, Uyo.

Subject and Method: A retrospective study of sixty-nine neonatal surgical cases seen over the first five years of existence of this hospital (2002 - 2006) was done. The information on age of admission, sex, weight, diagnosis, etc. were obtained from the admission register and case files.

Results: Eighty-nine (89.86\%) of the cases were outborn. The mean age of presentation was 6.67 days. The male: female ratio was 1:5:1. Thirty (43.8\%) were discharged while thirteen (18.84\%) died. Of those who died, omphalocele constituted the highest mortality of 53.85\% while spina bifida constituted the highest percentage among those who were referred (40\%) and amongst those who "left against Medical Advice" (31.25\%).

Conclusion: It is anticipated that with the growth of the hospital, improved neonatal facilities, more paediatric surgeons, availability of neonatal intensive care unit and a neurosurgeon, the outcome will improve as better peri-operative care, better trained inter-related sub-specialists, better imaging and laboratory facilities are desirable to enhance the outcome and survival in neonatal surgery here.

Keywords: Admissions; Congenital; Neonatal; Surgical

\section{Abbreviations}

MBBS: Bachelors of Medicine and Bachelors of Surgery; FWACP: Fellow of the West African College of Physicians; MD: Doctor of Medicine

\section{Introduction}

Congenital malformations are common in newborns as a result of developmental "accidents". Commonly, surgery in the newborn period mostly involves management of the congenital malformations and this has significantly contributed to the specialty of
"Paediatric surgery". Congenital malformations constitute $40 \%$ of neonatal surgery in some areas [1]. Most of the neonatal surgical cases are rare, occurring in $2-3 \%$ of live births [2]. They range from abdominal wall defects, oesophageal atresia with or without tracheo-oesophageal fistula, imperforate anus, intestinal obstruction, pyloric stenosis, teratoma, biliary atresia to choledochal cyst.

Paediatricians and neonatologists are usually the first recipients of these cases before they are evaluated for surgery by the surgeons. There is therefore the need for these two sets of specialists 
to work together to ensure appropriate temperature regulation, fluid balance, respiratory function and correction of metabolic deficits en route a successful surgical outcome [3]. In addition to the surgical procedure to be undertaken, good pre-operative preparation and post-operative management are necessary for a successful outcome.

Advances in technology and neonatal intensive care have led to improved safety and good outcome in neonatal surgery in developed countries but neonatal surgery in sub-Saharan Africa including Nigeria and Uyo in particular is still confronted with late presentations, inadequate personnel and equipments, poor finances on the parts of the parents and on the parts of the authorities [3]. Information regarding common neonatal surgical conditions in this South-South sub-region of Nigeria is lacking, personnels are inadequate and equipments are just basic. These together with the morbidities and mortalities observed among the newborns in this area have led to this retrospective study to profile the spectrum and outcome of neonatal surgical cases seen in the University of Uyo Teaching Hospital which was the only reference hospital at the time being reviewed (2002 - 2006).

\section{Method and Subjects}

This is a retrospective study carried out at the University of Uyo Teaching Hospital (then Federal Medical Centre) over a five-year period (2002 - 2006). The hospital was a tertiary hospital which served as a regional hospital for neonatal and other Specialist Care in Uyo and its environs which included Akwa Ibom State and some catchment areas from Abia State, Bakassi and occasionally the riverine areas of River State adjoining Akwa Ibom State. Its bed capacity then was 250 beds-with neonatal bed capacity of forty- two. It had at the period under review qualified Paediatric and other nurses, paediatricians, resident doctors and one Paediatric Surgeon. The data reviewed from case files were age of the neonate, sex, the types of neonatal surgical cases seen and outcome.

\section{Result}

Average age of presentation 6.67 days. Sixty- two (89.85\%) were out born while seven (10.15\%) were inborn.

The male female ratio was 1.56 to 1 .

\begin{tabular}{|l|c|c|c|c|c|c|}
\hline \multirow{2}{*}{ Gender } & \multicolumn{5}{|c|}{ Year } & \multirow{2}{*}{ Total } \\
\cline { 2 - 7 } & $\mathbf{2 0 0 2}$ & $\mathbf{2 0 0 3}$ & $\mathbf{2 0 0 4}$ & $\mathbf{2 0 0 5}$ & $\mathbf{2 0 0 6}$ & \\
\hline M & 9 & 5 & 4 & 12 & 12 & 42 \\
\hline F & 2 & 3 & 6 & 9 & 7 & 27 \\
\hline Total & 11 & 8 & 10 & 21 & 19 & 69 \\
\hline
\end{tabular}

Table 1: Distribution of sex of neonatal surgical cases by year.

\begin{tabular}{|c|c|c|c|c|c|c|}
\hline & \multicolumn{4}{|c|}{ Outcome } & \multicolumn{2}{|c|}{ Total } \\
\hline & Discharged & Died & Referred & LAMA & Frequency & Percentage \\
\hline Omphalocele & 6 & 7 & 2 & 1 & 16 & 23.17 \\
\hline Spina bifida & 2 & & 4 & 5 & 11 & 15.94 \\
\hline Imperforate Anus & 6 & 2 & & 3 & 11 & 15.94 \\
\hline Cleft lip/palate & 2 & & 1 & 1 & 4 & 5.80 \\
\hline Multiple congenital Malformation & 2 & 2 & & & 4 & 5.80 \\
\hline Intestinal Obstruction & 2 & 2 & & & 4 & 5.80 \\
\hline Hypospadia & 3 & & & 1 & 4 & 5.80 \\
\hline Gastric outlet obstruction & 2 & & 1 & & 3 & 4.35 \\
\hline Hirschsprung & 1 & & & & 1 & 1.45 \\
\hline Partial traumatic amputation of glands penis & 1 & & & & 1 & 1.45 \\
\hline Rt Inguino-scrotal hernia & 1 & & & & 1 & 1.45 \\
\hline Multiple fracture & 1 & & & & 1 & 1.45 \\
\hline Terratoma & 1 & & & & 1 & 1.45 \\
\hline Trachea-oesophageal fistula & & & 1 & & 1 & 1.45 \\
\hline Gastroschisis & & & & 1 & 1 & 1.45 \\
\hline Congenital hydrocephalous & & & 1 & & 1 & 1.45 \\
\hline Posterior urethral valve & & & & 1 & 1 & 1.45 \\
\hline Microcephaly with Encephalocele & & & & 1 & 1 & 1.45 \\
\hline Sublingual cyst & & & & 1 & 1 & 1.45 \\
\hline Hyper extension of knee joint & & & & 1 & 1 & 1.45 \\
\hline Total & 30 & 13 & 10 & 16 & 69 & 100 \\
\hline
\end{tabular}

Table 2: Distribution of neonatal surgical cases seen between 2002 - 2006. 


\begin{tabular}{|l|c|c|c|c|c|c|c|}
\hline \multirow{2}{*}{$\begin{array}{l}\text { Number of } \\
\text { cases }\end{array}$} & \multicolumn{5}{|c|}{ Year } & \multicolumn{2}{c|}{ Total } \\
\cline { 2 - 8 } & $\mathbf{2 0 0 2}$ & $\mathbf{2 0 0 3}$ & $\mathbf{2 0 0 4}$ & $\mathbf{2 0 0 5}$ & $\mathbf{2 0 0 5}$ & Frequency & $\%$ \\
\hline Discharged & 2 & 1 & 4 & 16 & 7 & 30 & 43.48 \\
\hline Referred & 4 & 2 & 1 & 0 & 3 & 10 & 14.49 \\
\hline LAMA & 1 & 3 & 4 & 4 & 4 & 16 & 23.19 \\
\hline Died & 4 & 2 & 1 & 1 & 5 & 13 & 18.84 \\
\hline Total & 11 & 8 & 10 & 21 & 19 & 69 & 100.00 \\
\hline
\end{tabular}

Table 3: Outcome of surgeries by year.

\begin{tabular}{|l|c|c|}
\hline Diagnosis & $\begin{array}{c}\text { Number of } \\
\text { deaths }\end{array}$ & $\begin{array}{c}\text { Percentage of } \\
\text { deaths }\end{array}$ \\
\hline Omphalocele & 7 & 53.85 \\
\hline Imperforate Anus & 2 & 15.38 \\
\hline Intestinal Obstruction & 2 & 15.38 \\
\hline $\begin{array}{l}\text { Multiple Congenital } \\
\text { Malformation }\end{array}$ & 2 & 15.38 \\
\hline Total & 13 & 100.00 \\
\hline
\end{tabular}

Table 4: Clinical conditions associated with mortality.

\begin{tabular}{|l|c|c|}
\hline Diagnosis & $\begin{array}{c}\text { Number of } \\
\text { referrals }\end{array}$ & $\begin{array}{c}\text { Percentage of } \\
\text { referrals }\end{array}$ \\
\hline Spina bidida & 4 & 40 \\
\hline Omphalocele & 2 & 20 \\
\hline Trachea-oesophageal fistula & 1 & 10 \\
\hline Gastric outlet obstruction & 1 & 10 \\
\hline Bilateral cleft of lip and palate & 1 & 10 \\
\hline Congenital hydrocephalous & 1 & 10 \\
\hline Total & 10 & 100 \\
\hline
\end{tabular}

Table 5: Distribution of neonatal surgical referrals.

\begin{tabular}{|l|c|c|}
\hline Diagnosis & $\begin{array}{c}\text { Number of } \\
\text { LAMA }\end{array}$ & $\begin{array}{c}\text { Percentage } \\
\text { of LAMA }\end{array}$ \\
\hline Spina bifida & 5 & 31.25 \\
\hline Imperforate Anus & 3 & 18.75 \\
\hline Posterior Urethral Valve & 1 & 6.25 \\
\hline Cleft Palate & 1 & 6.25 \\
\hline $\begin{array}{l}\text { Microcephaly with frontal encepha- } \\
\text { locele }\end{array}$ & 1 & 6.25 \\
\hline Gastroschisis & 1 & 6.25 \\
\hline Sublingual cyst & 1 & 6.25 \\
\hline Omphalocele & 1 & 6.25 \\
\hline Hyperextension of the knee joints & 1 & 6.25 \\
\hline Hypospadia & 1 & 6.25 \\
\hline Total & 16 & 100.00 \\
\hline
\end{tabular}

Table 6: Distribution of cases who left against medical advice.

\section{Discussion}

This was the neonatal surgical admission profile of the hospital in a period it was transiting from a specialist hospital to a Federal Medical Centre, then to a University Teaching Hospital. The commonest neonatal surgical admission was omphalocele. It constituted $23.7 \%$ of all neonatal surgical cases. This was followed spina bifida, imperforate anus, all congenital malformations. This mirrored similar situations in Malumfashi [5] and other areas [1] in North Central Nigeria where congenital malformations were the most common in the spectrum of pediatric surgical cases.

The near equal sex distribution of the surgical cases reflected similar sex distribution in the admission pattern and this may not have been of any particular significance.

Less than half of the patients were discharged home while about a quarter of the cases (23.19\%) "Left Against Medical Advice" and $14.9 \%$ were referred. These two groups constituted about a third of the cases seen. Spina bifida $(31.25 \%)$ and imperforate anus $(18.75 \%)$ constituted a larger percentage of those that "Left Against Medical Advice" while spina bifida and omphalocele constituted the highest percentages of those that were referred. The high percentage of those that "Left Against Medical Advice" was partly due to the poor perception of the outcome and the fact that parents bore $100 \%$ of the cost of care as there was no health insurance or charity organization to assist in financing the treatments. Also, at the period covering this review there was no neurosurgeon or plastic surgeon in the hospital. Additionally, in the course of counseling, the parents were made to understand that initial surgical treatment is lengthy and complex and they felt they couldn't bear the extra burden of having treatment in distant places.

What in most cases was done here as regards spina bifida was putting the babies on intravenous antibiotics, especially those that were open, leaking and infected and then subsequently referring them even though ideally the defect should be closed within the first two days of life. However there is a study that has shown that putting them on antibiotics in the first one week of life does not 
seems to adversely affect outcome [6].

In developing countries, it has been documented that most children typically present after the first day of life $[7,8]$ and the defect in grossly infected. Generally, pre-operative antibiotics are the rule in all settings but there is little to be gained in lengthy pre-operative antibiotics. Some of the spina bifida had associated other anomalies particularly chromosomal anomalies and this contributed to "Left Against Medical Advice" or being referred.

About one-fifth of those admitted died and omphalocele constituted the highest proportion (53.3\%) of those who died. This may not be unconnected with the fact that associated anomalies are said to be common in $45-88 \%$ of omphalocele and the severity of anomalies determine the prognosis [9]. Mortality is said to be close to $80 \%$ when associated anomalies are present and increase to $100 \%$ when chromosomal and cardiovascular anomalies are the ones present [10-13]. When omphalocele is isolated the prognosis is good and the mortality is $10 \%$. Lack of advanced imaging capability, poor funding and inability to do chromosomal studies made in difficult to know the exact extent of associated anomalies in this study.

Most of the outcomes were related to shortage of trained personnel. As at the period under review, there was only one paediatric surgeon who worked with general medical officers and was also saddled with administrative duties. There was also lack of appropriate facilities such as well equipped laboratory, radiological facilities and facilities for advanced imaging procedures. There was no neonatal intensive care unit and for those on long-term postoperative-nil per oris, parental nutrition was not done as this was not readily available. Intravenous nutrition is one of the significant advances in neonatal surgery where the surgical stress increases the newborn caloric requirement.

Other challenging problems arising from lack of appropriately trained personnel that was encountered in neonatal surgical care here was the lack of understanding of the neonatal physiology and basic knowledge of metabolic changes and fluid and electrolyte management. This was a problem because the medical officers were yet to have specialized training. The transition from specialist Medical Centre to Federal Medical Centre to the University Teaching Hospital had seen some of these inadequacies being addressed. Paediatric Surgical unit has gradually evolved. Local training and certification of resident doctors have been started.

Nigeria's fertility rate of 5.39 is still relatively high [14] considering Nigeria's present population of about $200 \mathrm{~m}$, it is expected that the high fertility rate will be directly related to a high prevalence of congenital anomalies. This means that more attention should be paid to neonatal surgical services. The quality of neonatal surgical services reflects the quality of paediatric surgical services. This study was to determine the pattern of admissions of neonatal surgical cases at the formative stage of the hospital with a view of to using the outcome variables to give direction to the planning and improvement of the neonatal surgical services.

Survival in neonatal surgery is related to better peri-operative care, good technical skills and treatment of associated anomalies. These are now being enhanced here. There are now two paediatric surgeons, two plastic surgeons and a neurosurgeon. Even though local training and certification has given rise to directed mentoring of resident doctors, there is still absence of neonatal intensive care unit. There is also need for political will to sufficiently fund the neonatal unit as there is usually the feeling that income from neonatal unit is not commensurate with the money expended on the unit and so funding is commonly withheld or not proportionately allocated.

\section{Conclusion}

It is anticipated that with the growth of the hospital, improved neonatal facilities, more paediatric surgeons, availability of neonatal intensive care unit and a neurosurgeon, the outcome will improve as better peri-operative care, better trained inter-related sub-specialists, better imaging and laboratory facilities are desirable to enhance the outcome and survival in neonatal surgery here.

\section{Source of Funding}

No source of funding.

\section{Author Contribution}

Eno Nyong: Conception, design and drafting of the manuscript.

Usen Uwah: Review of the first manuscript draft.

Jacob Udoh: Review of the first manuscript draft.

Paulinus Essien: Collection of data and drafting of the manuscript.

Kingsley Akhimeinho: Data analysis and review of manuscript.

All the authors read and approved the final drafting.

\section{Conflict of Interest}

The authors declare no conflict of interest.

\section{Ethical Considerations}

Ethical approval was sought from the institutional Health re-

\section{Bibliography}

1. Ameh EA., et al. "Neonatal Surgical Care. A review of the burden, progress and challenges in sub-saharan Africa”. Pediatrics and International Health 35.3 (2015): 243-252.

2. Sadler TW. "Birth defects and prenatal diagnosis". In Langman's Medical embryology. $13^{\text {th }}$ Edition. Philadephelphia Walters Kluver (2015): 126-140. 
3. Bagga D. "Neonatal Surgery". Journ Neonatal 21.4 (2007).

4. Ameh EA. "Challenges of neonatal surgery in sub-saharan Africa". African Journal of Paediatric Surgery 1 (2004): 43-48.

5. Ameh EA and Chirdan L. "Pediatric Surgery in rural setting: prospect and feasibility". West African Journal of Medicine 20.1 (2001): 52-55.

6. Park TS. "Myelomeningocele”. In Albright L, Adelson D. editors. Principles and practices of Paediatrics Neurosurgery. New York: Thieme Medical Publishers (1999): 291-320.

7. Kumar R and Singh SN. "Spinal dysraphysm trends in Northern India”. Pediatric Neurosurgery 38.3 (2003): 133-145.

8. Buccimazza S., et al. "Pre-School follow up of a cohort of children with Myelomeningocele in Cape Town, South Africa". Annals of Tropical Paediatrics 19.3 (1999): 245-252.

9. Lunzer H., et al. "Long term follow up of the children with prenatally diagnosed omphalocele and gastroschisis". Journal of Maternal-Fetal and Neonatal Medicine 10.6 (2001): 385-392.

10. Boyd PA., et al. "Outcome of prenatally diagnosed anterior abdominal wall defects". Archives of Disease in Childhood 78.3 (1998): 209-213.

11. Dimitrion G., et al. "Morbidity in infants with antenatally-diagnosed anterior abdominal wall defects". Pediatric Surgery International 16.5-6 (2000): 404-407.

12. Fisher R., et al. "Impact of antenatal diagnosis on incidence and prognosis in abdominal wall defects". Journal of Pediatric Surgery 31.4 (1996): 538-541.

13. Van Eijck FC., et al. "The incidence and morbidity of adhesions after treatment of neonates with gastroschisis and omphalocele: a 30-year review". Journal of Pediatric Surgery 43.3 (2008): 479-480.

14. Varella S. "Demographics of Nigeria-Statistics and facts" (2020).

\section{Assets from publication with us}

- Prompt Acknowledgement after receiving the article

- Thorough Double blinded peer review

- Rapid Publication

- Issue of Publication Certificate

- High visibility of your Published work

Website: www.actascientific.com/

Submit Article: www.actascientific.com/submission.php

Email us: editor@actascientific.com

Contact us: +919182824667 